\title{
Chlorococcales (Chlorophyceae) de um tributário do Reservatório de Itaipu, Paraná, Brasil
}

\author{
Stefania Biolo ${ }^{1}$, Natália Silveira Siqueira ${ }^{1}$ e Norma Catarina Bueno ${ }^{2,3}$
}

Recebido: 21.02.2008; aceito: 13.11.2009

\begin{abstract}
Chlorococcales (Chlorophyceae) from a tributary of Itaipu reservoir, Paraná, Brasil). This work aimed the taxonomic knowledge of the order Chlorococcales (Chlorophyceae) from São Francisco Falso River, one of the Itaipu reservoir tributaries located at the municipal district of Santa Helena, Paraná State, Brazil. Samples were collected from July 2003 to June 2004 at five sample stations located in the litoral region of the river. The phytoplanktonic material, obtained with plankton net ( $25 \mu \mathrm{m}$ net) and by passing open flasks on water surface, were immediately fixed in Transeau solution. The qualitative sample analysis allowed the identification of 21 taxa belonging to the families: Palmellaceae, Hydrodictyaceae, Botryococcaceae, Chlorellaceae, Coelastraceae and Scenedesmaceae. The most representative genus was Desmodesmus with seven taxa. Hydrodictyon reticulatum (L.) Lagerheim and Coelastrum astroideum De Notaris var. astroideum were firstly cited in the Paraná State.
\end{abstract}

Key words: Phytoplankton, reservoir, taxonomy

RESUMO - (Chlorococcales (Chlorophyceae) de um tributário do Reservatório de Itaipu, Paraná, Brasil). O trabalho objetivou o conhecimento taxonômico da ordem Chlorococcales (Chlorophyceae) do Rio São Francisco Falso, um dos tributários do reservatório de Itaipu, Paraná, Brasil. As amostras foram coletadas no período de julho de 2003 a junho de 2004 em cinco estações de amostragem localizadas na região litorânea do rio. O material fitoplanctônico, obtido com rede de plâncton $(25 \mu \mathrm{m}$ de malha) e passagem de frasco aberto pela superfície da água, foi imediatamente fixado em solução de Transeau. A análise qualitativa das amostras possibilitou a identificação de 21 táxons distribuídos nas famílias: Palmellaceae, Hydrodictyaceae, Botryococcaceae, Chlorellaceae, Coelastraceae e Scenedesmaceae. O gênero mais representativo foi Desmodesmus, com sete táxons do total. Hydrodictyon reticulatum (L.) Lagerheim e Coelastrum astroideum De Notaris var. astroideum são citadas pela primeira vez para o Estado do Paraná.

Palavras-chave: Fitoplâncton, reservatório, taxonomia

\section{Introdução}

O conhecimento atual das Chlorococcales do Estado do Paraná resume-se a nove trabalhos, dos quais seis têm enfoque taxonômico e quatro incluem aspectos ecológicos. Picelli-Vicentim (1987) registrou pela primeira vez, 61 táxons de Chlorococcales do Parque Regional do Iguaçu, Curitiba e destes, 58 táxons são as primeiras citações para o Estado e dois para o Brasil. Rodrigues \& Train (1993), identificaram 30 táxons de Chlorococcales para o lago do Parque Alfredo Nyffeler, Maringá e destes, 16 táxons são os primeiros registros para o Estado. Oliveira et al. (1994) contribuíram também com a identificação de 30 táxons de Chlorococcales no levantamento da flora fitoplanctônica do Rio Paraná e Canal Cortado, na planície de inundação do alto Rio Paraná. Bittencourt-Oliveira (1997) documentou 24 táxons de Chlorococcales no rio Tibagi, principal afluente do rio Paranapanema. Picelli-Vicentim et al. (2001) registraram 22 táxons de Chlorococcales na comunidade fitoplanctônica do Reservatório de Passaúna, Curitiba. Moresco \& Bueno (2007) registraram 21 táxons de Chlorococcales no reservatório urbano do município de Cascavel, sendo 13 pertencentes ao gênero Desmodesmus An, Friedl \& Hegewald e oito pertencentes ao gênero Scenedesmus Meyen. Os trabalhos de Andrade e Rachou (1954), Moreira Filho \& Moreira (1972) e Cecy (1986)

1. Universidade Estadual de Maringá, Departamento de Biologia, Nupélia, Av. Colombo, 5790, 87020-900 Maringá, PR, Brasil

2. Universidade Estadual do Oeste do Paraná, Centro de Ciências Biológicas e da Saúde, Rua Universitária, 2069, 85814-110 Cascavel, PR, Brasil

3. Autor para correspondência: ncbueno@unioeste.br 
incluem listagens de gêneros ou espécies em trabalhos com aspectos ecológicos.

Portanto o presente trabalho objetivou o inventário florístico das Chlorococcales de um tributário do Reservatório de Itaipu, contribuindo assim com os estudos de biodiversidade ficológica do Estado do Paraná.

\section{Material e métodos}

O Reservatório de Itaipu, localizado na fronteira Brasil-Paraguai $\left(24^{\circ} 05^{\prime}-25^{\circ} 33^{\prime}\right.$ S e $54^{\circ} 00^{\prime}-54^{\circ} 37^{\prime}$ W), com $170 \mathrm{~km}$ de extensão e $12 \mathrm{~km}$ de largura, foi formado pela inundação de oito tributários (Agostinho et al. 1999). O Rio São Francisco Falso, com área total de $38,8 \mathrm{~km}^{2}$ e foz no trecho médio do reservatório (figura 1a), é o principal formador da área alagada do município de Santa Helena, no oeste do Paraná. Apresenta trechos com características de ambiente lêntico, tem importância sócio-econômica considerável para a região, sendo utilizado tanto para fins recreativos pela população urbana como também para a irrigação de áreas cultivadas.

As coletas foram realizadas mensalmente, no período de julho de 2003 a junho de 2004, em cinco estações de amostragem na região litorânea ao longo do Rio São Francisco Falso, totalizando 60 amostras,

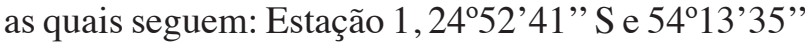
W; Estação 2, 24'52'28' S e 54 15'17' W; Estação 3, 2451'52" S e 54 16'02" W; Estação 4, 24 51'30" S e 54 17'11"W e Estação 5, 2451'14"'S e 54 17'11' 'W (figura 1b). As 60 amostras foram obtidas com rede de

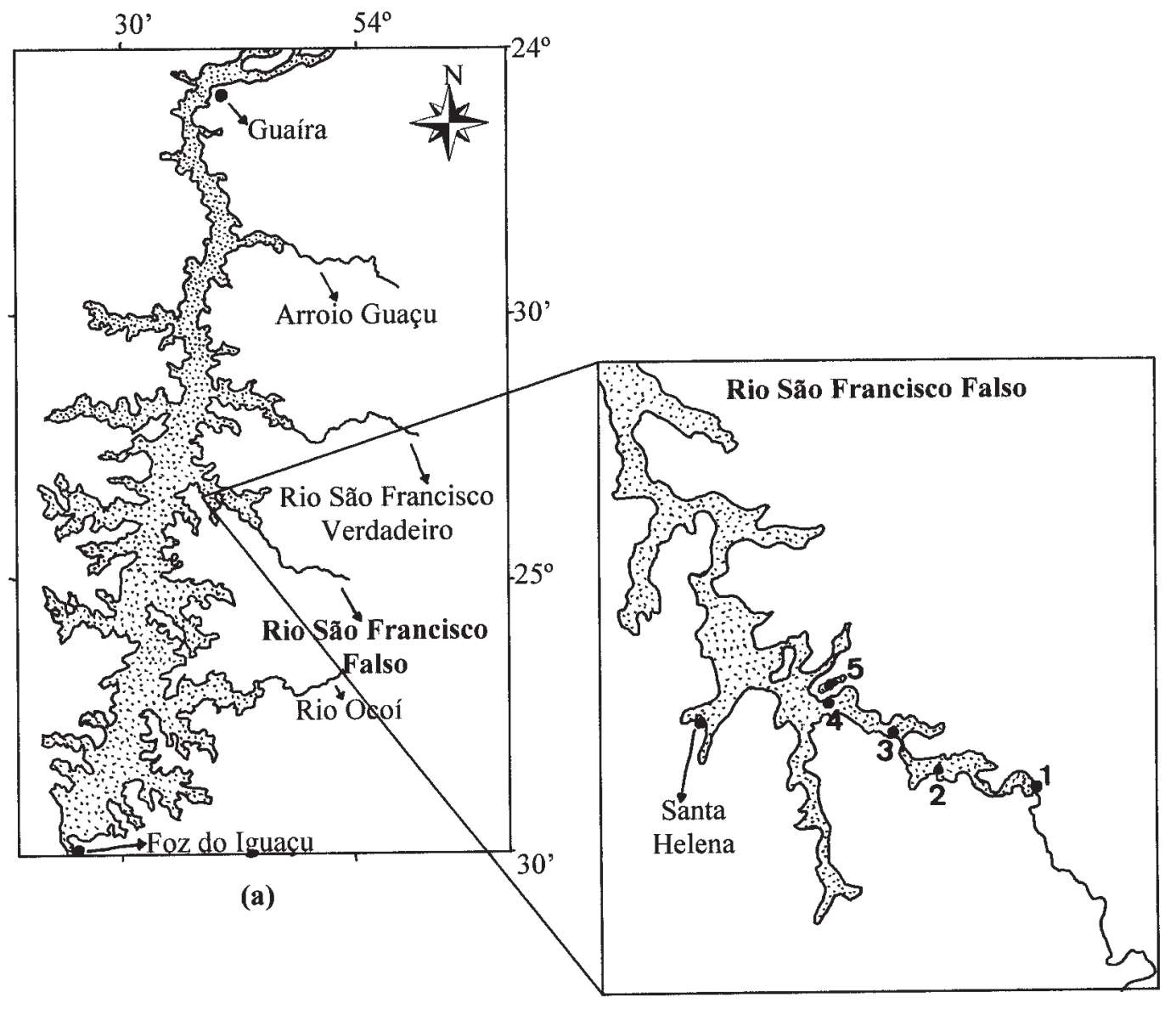

(b)

Figura 1. Localização da área de estudo no Reservatório de Itaipu (a) e das estações de coleta (1-5) no Rio São Francisco Falso (b), Paraná, Brasil.

Figure 1. Location of the study area in the Itaipu Reservoir (a) and the collect stations (1-5) in the São Francisco Falso River (b), Paraná, Brazil. 
plâncton de malha de $25 \mu \mathrm{m}$ de abertura e passagem de frasco aberto pela superfície da água, imediatamente conservadas em solução Transeau, na proporção 1:1 (Bicudo \& Menezes 2006).

Para as análises qualitativas foram preparadas lâminas temporárias, em média 10 lâminas por amostra ou até não ocorrerem táxons diferentes. As análises taxonômicas foram realizadas com microscópio binocular e câmara clara em aumento de 400 e $1.000 \times$. As amostras foram depositadas no Herbário da Universidade Estadual de Maringá (HUEM) sob as numerações 859 a 12671.

O enquadramento sistemático das famílias seguiu Komárek \& Fott (1983). A identificação das espécies e variedades foi feita de acordo literatura especializada: Sant'Anna (1984), Ettl \& Gärtner (1988), Hegewald \& Silva (1988), Nogueira (1991), Comas (1996) e Hegewald (2000).

As medidas (em $\mu \mathrm{m})$ estão representadas pelos símbolos: diâm. $=$ diâmetro; compr. $=$ comprimento; larg. $=$ largura; proc. $=$ processo $(\mathrm{s}) ;$ esp. $=\operatorname{espinho}(\mathrm{s})$; dent.$=$ dente $(\mathrm{s})$.

\section{Resultados e Discussão}

Foram identificados 21 táxons da ordem Chlorococcales distribuídos nas famílias: Palmellaceae, Hydrodictyaceae, Botryococcaceae, Chlorellaceae, Coelastraceae e Scenedesmaceae. A família Scenedesmaceae apresentou o maior número de táxons (10), o gênero mais representativo foi Desmodesmus, com sete táxons no total. Duas espécies são citadas pela primeira vez para o Estado do Paraná, Hydrodictyon reticulatum (L.) Lagerheim e Coelastrum astroideum De Notaris var. astroideum.

\section{Chlorophyceae}

Chlorococcales

\section{PALMELLACEAE}

Sphaerocystis schroeteri Chodat, Bull. Herb. Boissier 5: 119. 1897.

Figura 2

Colônias esféricas, células dispostas irregularmente numa mucilagem homogênea, colônias-filhas de 4-8 células podem estar presentes; células esféricas, 4-11 $\mu \mathrm{m}$ diâm.; cloroplasto parietal ou poculiforme, com um pirenóide basal.

Material examinado: BRASIL. Paraná: Santa Helena, Rio São Francisco Falso, 1-VII-2003, N.C. Bueno 885 (HUEM); idem, 1-IX-2003, N.C. Bueno 874 (HUEM); idem, 17-VI-2004, N.C. Bueno 937 (HUEM); idem, 28-VII-2003, N.C. Bueno 862 (HUEM); idem, 5-IV2004, N.C. Bueno 925 (HUEM).

Ocorrência no Paraná: Parque Regional do Iguaçu (Picelli-Vicentim 1987).

Picelli-Vicentim (1987) apresentou uma breve discussão sobre as semelhanças morfológicas existentes entre Sphaerocystis schroeterii Chodat e S. planctonica (Korsikov) Bourrelly. Segundo a autora, os atributos métricos propostos por Komárek \& Fott (1983) são insuficientes para a separação das espécies. São necessários estudos sobre os aspectos reprodutivos das espécies, afim de melhor esclarecer a delimitação taxonômica conforme proposto por Sant'Anna (1984) e Nogueira (1991).

\section{HYDRODICTYACEAE}

Chave para identificação das espécies e variedades encontradas

1. Cenóbio reticulado, células cilíndricas Hydrodictyon reticulatum

1. Cenóbio esférico ou plano, células de outras formas

2. Cenóbio esférico, células com pedúnculos Sorastrum americanum var. americanum

2. Cenóbio plano, células sem pedúnculos

3. Cenóbios quadráticos, espaços intercelulares ausentes Pediastrum tetras var. tetras

3. Cenóbios circulares, espaços intercelulares presentes

4. Células externas do cenóbio com dois processos curtos, cônicos P. duplex var. duplex

4. Células externas do cenóbio com um único processo, longo, cilíndrico ....P. simplex var. simplex 
Hydrodictyon reticulatum (L.) Lagerheim, Öfvers. K. [Svenska] Vet.-Akad. Förh. 40(2): 71. 1883 $\equiv$ Conferva reticulata Linnaeus, Sp. pl. 2: 1165. 1753.

Figura 3

Cenóbios reticulados, células dispostas de forma pentagonal ou hexagonal, unidas pelos pólos; células cilíndricas 8,4-69,4 um compr., 4,2-24,1 $\mu \mathrm{m}$ larg.; cloroplasto parietal, 4-8 pirenóides.

Material examinado: BRASIL. PARANÁ: Santa Helena, Rio São Francisco Falso, 1-IX-2003, N.C. Bueno 12625 (HUEM).

Ocorrência no Paraná: Primeira citação da espécie.

Para o Brasil Hydrodictyon reticulatum constituise a única espécie conhecida (Bicudo \& Menezes 2006).

Pediastrum duplex Meyen var. duplex, Verhandl. Kgl. Leop. Carol. Akad. Naturf. 14: 772. 1829.

Figura 4

Cenóbios circulares ou oblongos, formados por 8-16-32 células dispostas concentricamente, espaços intercelulares presentes; células externas poligonais unidas pela base, ápices truncados, com dois processos, cônicos, curtos; células internas poligonais ou quase retangulares. Cenóbios 42,4-63,2 $\mu$ m diâm., células externas 6,4-18,4 $\mu \mathrm{m}$ compr., 6,4-12,2 $\mu \mathrm{m}$ larg., células internas 6,4-12,2 um compr., 6,4-12,2 $\mu \mathrm{m}$ larg.; parede celular lisa, cloroplasto parietal, com um pirenóide.

Material examinado: BRASIL. PARANÁ: Santa Helena, Rio São Francisco Falso, 28-VII-2003, N.C. Bueno 862 (HUEM); idem, 5-IV-2004, N.C. Bueno 925 (HUEM).

Ocorrência no Paraná: Parque Regional do Iguaçu (Picelli-Vicentim 1987); Parque Alfredo Nyffeler (Rodrigues \& Train 1993); Rio Paraná e Canal Cortado (Oliveira et al. 1994); Rio Tibagi (Bittencourt-Oliveira 1997); Reservatório do Passaúna (Picelli-Vicentim et al. 2001).

As formas cenobiais de Pediastrum duplex encontradas no presente estudo, apresentaram 8-1632 células. De acordo com Sant'Anna (1984) podem formar cenóbios com 64-128 células. Os indivíduos examinados apresentaram dimensões pouco maiores, quando comparados com os registros de BittencourtOliveira (1997). A autora registrou os maiores valores no tamanho celular (células externas 9,5-20 $\mu \mathrm{m}$ compr., 6,2-20,0 $\mu \mathrm{m}$ larg., células internas 6,5-15 $\mu \mathrm{m}$ compr., 8-18 $\mu \mathrm{m}$ larg).

Pediastrum simplex Meyen var. simplex, Verhandl. Kgl. Leop. Carol. Akad. Naturf. 14: 772. 1829.

Figura 5

Cenóbios circulares, formados por 8-16 células, espaços intercelulares presentes; células externas trapezóides, com um processo cilíndrico longo, unidas pela região mediana das margens celulares; células internas piramidais a poligonais. Cenóbios 85-95,9 um diâm.; células externas 24-35 um compr., 9-16 um larg.; células internas 11-28 um compr., 11$16 \mu \mathrm{m}$ larg.; parede celular lisa, cloroplasto parietal, com um pirenóide.

Material examinado: BRASIL. PARANÁ: Santa Helena, Rio São Francisco Falso, 6-X-2003, N.C. Bueno 883 (HUEM); idem, 8-XII-2003, N.C. Bueno 902 (HUEM).

Ocorrência no Paraná: Parque Regional do Iguaçu (Picelli-Vicentim 1987); Rio Paraná e Canal Cortado (Oliveira et al. 1994); Rio Tibagi (Bittencourt-Oliveira 1997).

Pediastrum tetras (Ehrenberg) Ralfs var. tetras, Ann. Mag. Nat. Hist. 14: 469. $1845 \equiv$ Micrasterias tetras Ehrenberg, Infus.: 155. 1838.

Figura 6

Cenóbios circulares ou quadráticos, formados por 4-8 células dispostas concentricamente, espaços intercelulares ausentes; células poligonais com incisão linear a arcuada formando processos bifurcados; células internas quadráticas a hexagonais, incisão linear em um dos lados, 5,6-6,1 $\mu \mathrm{m}$ compr., 4,4-5 um larg. (com proc.); parede celular lisa, cloroplasto parietal, com um pirenóide.

Material examinado: BRASIL. PARANÁ: Santa Helena, Rio São Francisco Falso, 5-IV-2004, N.C. Bueno 925 (HUEM).

Ocorrência no Paraná: Parque Regional do Iguaçu (Picelli-Vicentim 1987); Parque Alfredo Nyffeler (Rodrigues \& Train 1993); Rio Paraná e Canal Cortado (Oliveira et al. 1994); Reservatório do Passaúna (Picelli-Vicentim et al. 2001). 
Sorastrum americanum (Bohlin) Schmidle var. americanum, Engler's bot. Jb. 27: 230. 1900.

Figura 7

Cenóbio esférico, formado por 16 células dispostas radialmente; células piramidais, com dois processos, afilados, longos, células afiladas em pedúnculos delgados unidos em suas bases poligonais, formando uma estrutura central esférica. Cenóbio 52-75 um diâm., células 16-20 um compr. (com pedúnculos), 5-16 $\mu \mathrm{m}$ larg.; proc. 5-9 $\mu \mathrm{m}$ compr.; pedúnculos 7,5-9 $\mu \mathrm{m}$ compr.; cloroplasto parietal, com um pirenóide.

Material examinado: BRASIL. PARANÁ: Santa Helena, Rio São Francisco Falso, 6-X-2003, N.C. Bueno 883 (HUEM).

Ocorrência no Paraná: Parque Regional do Iguaçu (Picelli-Vicentim 1987).

Sorastrum americanum var. americanum apresenta as margens laterais dos pedúnculos retas. PicelliVicentim (1987) registrou também S. americanum (Bohlin) Schmidle var. undulatum G. M. Smith, que apresenta as margens dos pedúnculos onduladas e $S$. spinulosum Nägeli, distinta de $S$. americanum var. americanum que possui projeções e pedúnculos mais curtos (a célula atinge o comprimento total 6-13 $\mu \mathrm{m}$ ).

\section{BOTRYOCOCCACEAE}

Dictyosphaerium pulchellum Wood, Smithson. Contr. Knowl. 19: 84. 1873.

Figura 8

Colônias esféricas ou ovóides, formadas por grupos de 4 células unidas por pedúnculos mucilaginosos, ramificados, envoltos por mucilagem; células adultas esféricas, as jovens podem ser ovóides, 3,5-7,5 um diâm.; cloroplasto poculiforme, com um pirenóide basal.

Material examinado: BRASIL. PARANÁ: Santa Helena, Rio São Francisco Falso, 1-VII-2003, N.C. Bueno 855 (HUEM); 5-IV-2004, N.C. Bueno 925 (HUEM).

Ocorrência no Paraná: Parque Regional do Iguaçu (Picelli-Vicentim 1987); Rio Paraná e Canal Cortado (Oliveira et al. 1994); Rio Tibagi (Bittencourt-Oliveira 1997).

Difere de Dictyosphaerium ehrenbergianum Nägeli pelo formato ovóide das células. Em $D$. pulchellum as células adultas são tipicamente esféricas.

\section{CHLORELLACEAE}

Chave para identificação das espécies encontradas

1. Colônias com numerosas células (no mínimo 30), torcidas, fusiformes, arcuadas a sigmóides .... Ankistrodesmus densus

1. Colônias com duas ou mais células (no máximo 16), cruzadas umas sobre as outras, fusiformes, arcuadas a retas Ankistrodesmus fusiformis

Ankistrodesmus densus Kor $\square \mathrm{kov}$, Protococcineae: 300. 1953.

Figura 9

Colônias com numerosas células16-32, densamente reunidas, torcidas umas sobre as outras ou superpostas; células fusiformes, arcuadas, afiladas

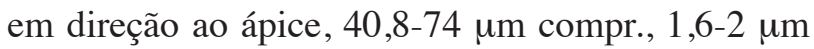
larg.; cloroplasto parietal, pirenóides ausentes.

Material examinado: BRASIL. PARANÁ: Santa Helena, Rio São Francisco Falso, 1-VII-2003, N.C. Bueno 859 (HUEM).

Ocorrência no Paraná: Parque Regional do Iguaçu (Picelli-Vicentim 1987); Parque Alfredo Nyffeler (Rodrigues \& Train 1993); Rio Paraná e Canal Cortado (Oliveira et al. 1994).

Ankistrodesmus fusiformis Corda sensu Kor $\square \mathrm{kov}$, Protococcineae: 300. 1953.

Figura 10

Colônias com 4-8-16 células, dispostas radialmente ou de forma cruciada; células fusiformes, retas a arcuadas, afiladas em direção ao ápice, 3691,8 um compr., 1-3,2 um larg.; cloroplasto parietal, pirenóides ausentes.

Material examinado: BRASIL. Paraná: Santa Helena, Rio São Francisco Falso, 1-VII-2003, N.C. Bueno 855 (HUEM); idem, 8-XII-2003, N.C. Bueno 902 (HUEM); idem, 5-IV-2004, N.C. Bueno 925 (HUEM).

Ocorrência no Paraná: Parque Regional do Iguaçu (Picelli-Vicentim 1987); Parque Alfredo Nyffeler (Rodrigues \& Train 1993). 


\section{COELASTRACEAE}

Chave para identificação das espécies e variedades encontradas

1. Cenóbios formados por células octogonais, com processos unindo as células ....... Coelastrum pulchrum var. pulchrum

1. Cenóbios formados por células ovóides, sem processos unindo as células C. astroideum var. astroideum

Coelastrum astroideum De Notaris var. astroideum, Elem. Stud. Desm. Ital.: 80. 1867.

Figura 11

Cenóbios esféricos, formados por 8(-16-32) células, espaços intercelulares presentes, quadrangulares; células ovóides, processos entre as células ausentes. Cenóbio 17,5-20 um diâm., células 5,6-8,5 um diâm.; parede celular lisa, frequentemente com espessamento apical, cloroplasto parietal, com um pirenóide.

Material examinado: BRASIL. PARANÁ: Santa Helena, Rio São Francisco Falso, 28-VII-2003, N.C. Bueno 862 (HUEM).
Ocorrência no Paraná: Primeira citação da espécie.

Coelastrum astroideum De Notaris var. astroideum assemelha-se muito a Coelastrum microporum Nägeli, porém difere por possuir células ovóides e não esféricas.

Coelastrum pulchrum Schmidle var. pulchrum, Ber. Dt. Bot. Ges. 10: 206. 1892.

Figura 12

Cenóbios esféricos, formados por (8-)16(-32) células, espaços intercelulares presentes; células octogonais, unidas por processos cônico-truncados, voltados para a periferia do cenóbio, ápices espessados. Cenóbio 56-64 ㅆm diâm., células 18-24 um diâm.; cloroplasto parietal, com um pirenóide.

Material examinado: BRASIL. Paraná: Santa Helena, Rio São Francisco Falso, 19-I-2004, N.C. Bueno 855 (HUEM).

Ocorrência no Paraná: Rio Paraná e Canal Cortado (Oliveira et al. 1994); Reservatório do Passaúna (Picelli-Vicentim et al. 2001).

\section{SCEMEDESMACEAE}

Chave para identificação das espécies e variedades encontradas

1. Cenóbios formados por grupos de 4-8 células unidas por fios mucilaginosos ramificados; grupos com duas células ovóides e duas cordiformes ou reniformes Dimorphococcus lunatus

1. Cenóbios formados por $2(-32)$ células, unidas na maioria das vezes pela margem ao longo do maior eixo da célula; células de formas variadas

2. Células com ornamentações (espinhos, costelas)

3. Parede da célula externa ornamentada com espinhos longos

4. Espinho longo em apenas um dos ápices das células externas

4. Espinho longo nos dois ápices das células externas

Desmodesmus armatus var. bicaudatus

5. Células ornamentadas com costelas e/ou dentes

6. Células ornamentadas com costelas, inteiras ou interrompidas, células internas terminadas em dentes D. armatus var. armatus

6. Células externas e internas ornamentadas com dentes

7. Células oblongas, de disposição linear D. denticulatus var. linearis

7. Células ovóide-elípticas, de disposição alternada

D. denticulatus var. denticulatus

5. Células sem esta ornamentação

8. Pólos arredondados; células unidas ao longo de todo o comprimento D. communis

8. Pólos cônico-arredondados; células unidas ao longo de $2 / 3$ do eixo maior ... D. protuberans

3. Parede da célula externa com outros tipos de ornamentação 
9. Células do cenóbio ornamentadas com costelas D. brasiliensis

9. Células do cenóbio sem costelas

10. Células ovóides a oblongas, dispostas linearmente D. denticulatus var. linearis 10. Células ovóide-elípticas a amplamente ovóides, dispostas alternadamente

D. denticulatus var. denticulatus

2. Células sem ornamentações (espinhos, costelas)

11. Células externas e internas dos cenóbios iguais, elípticas a cilíndrico-elípticas

Scenedesmus ecornis

11. Células externas e internas dos cenóbios diferentes, fusiformes, células externas afiladas levemente curvadas para fora do cenóbio S. acutus

Dimorphococcus lunatus A. Braun, Alg. unicell.: 44. 1855.

Figura 13

Colônias circulares, formadas por grupos de 4-8 células unidos por fios mucilaginosos ramificados, dispostas alternadamente; células externas reniformes a cordiformes, células internas oblongas, células 5-8 $\mu \mathrm{m}$ compr., 7,2-15 $\mu \mathrm{m}$ larg.; cloroplasto parietal,com um pirenóide.

Material examinado: BRASIL. PARANÁ: Santa Helena, Rio São Francisco Falso, 1-VII-2003, N.C. Bueno 855 (HUEM).

Ocorrência no Paraná: Parque Regional do Iguaçu (Picelli-Vicentim 1987); Rio Paraná e Canal Cortado (Oliveira et al. 1994); Reservatório do Passaúna (Picelli-Vicentim et al. 2001).

Scenedesmus ecornis (Ehreberg ex Ralfs) Chodat var. ecornis, Z. Hidrol. 3: 170. 1926 = Scenedesmus quadricaudatus var. ecornis Ehrenberg ex Ralfs, Ann. \& Mag., Nat. Hist. 15: 402. 1845.

Figura 14

Cenóbios formados por (2-)4(-8) células dispostas linearmente; células elípticas a cilíndrico-elípticas, 12,2-24,4 um compr., 6,1-16,3 $\mu \mathrm{m}$ larg.; parede celular lisa, cloroplasto parietal, com um pirenóide.

Material examinado: BRASIL. PARANÁ: Santa Helena, Rio São Francisco Falso, 1-VII-2003, N.C.Bueno 855 (HUEM); idem, 1-IX-2003, N.C.Bueno 874 (HUEM); idem, 6-X-2003, N.C. Bueno 883 (HUEM); idem, 8-XII-2003, N.C. Bueno 902 (HUEM).

Ocorrência no Paraná: Reservatório do Passaúna (Picelli-Vicentim et al. 2001); Lago Municipal de Cascavel (Moresco \& Bueno 2007).
Scenedesmus acutus Meyen, Verhandl. Kgl. Leop. Carol. Akad. Naturf. 14: 775. 1829.

Figura 15

Cenóbios formados por 4 células dispostas linearmente; células fusiformes, as externas retas, com margem externa levemente convexa, pólos curvados levemente para a periferia do cenóbio; células internas retas, margens das células internas convexas, 12-17,6 $\mu \mathrm{m}$ compr., 10-12,6 $\mu \mathrm{m}$ larg.; cloroplasto parietal, com um pirenóide.

Material examinado: BRASIL. PARANÁ: Santa Helena, Rio São Francisco Falso, 1-IX-2003, N.C. Bueno 874 (HUEM); idem, 10-III-2004, N.C. Bueno 918 (HUEM).

Ocorrência no Paraná: Parque Regional do Iguaçu (Picelli-Vicentim 1987); Rio Tibagi (BittencourtOliveira 1997); Lago Municipal de Cascavel (Moresco \& Bueno 2007).

Aidentificação de Scenedesmus acutus foi baseada na forma das células e no âmbito populacional. A espécie caracteriza-se por apresentar células externas e internas sempre retas podendo ocorrer células externas com pólos levemente curvados para a periferia do cenóbio. Difere de S. acuminatus (Lagerheim) Chodat que apresenta as células externas fortemente curvadas para a periferia do cenóbio. Felisberto et al. (2001) diferenciam as duas espécies com base na curvatura das células e nas dimensões celulares ( $S$. acutus, 10,44-18,27 compr. e 2,61-5,22 larg.; S. acuminatus, 36,54-44,37 compr. e 5,22 larg.). Tais caracteres também foram utilizados no presente trabalho para a identificação de S. acutus, no entanto, a largura celular dos indivíduos registrados foi ampliada.

Desmodesmus armatus (Chodat) Hegewald var. armatus, Arch. Hydrobiol. Suppl. 131: 2. 2000 =Scenedesmus hystrix var. armatus, Alg. Vert. Suisse: 215. 1902. 

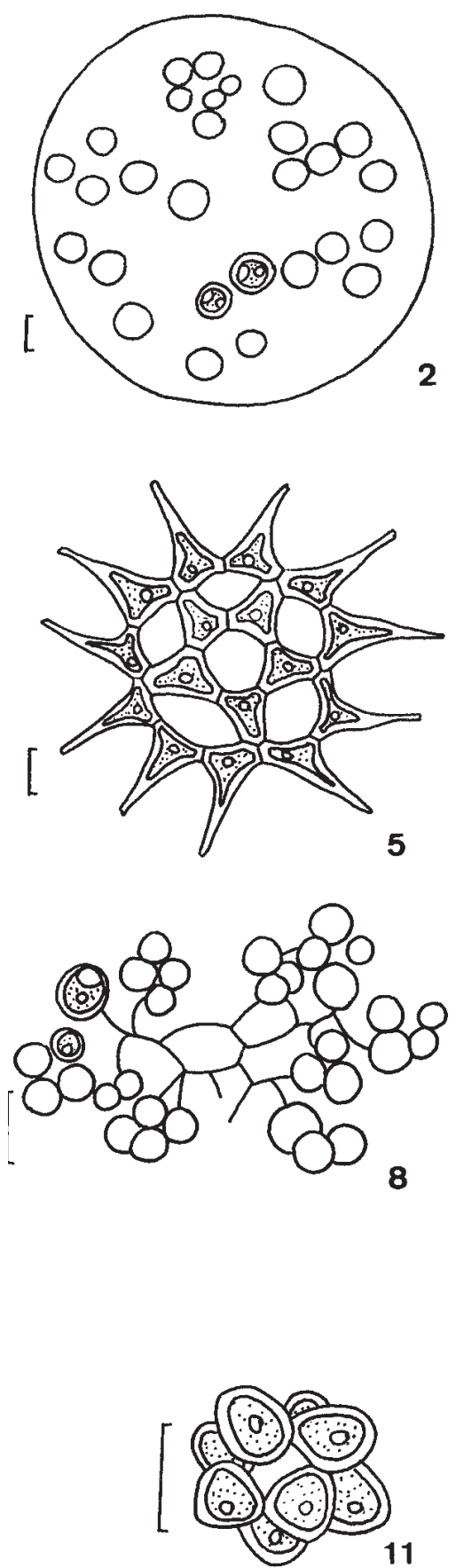
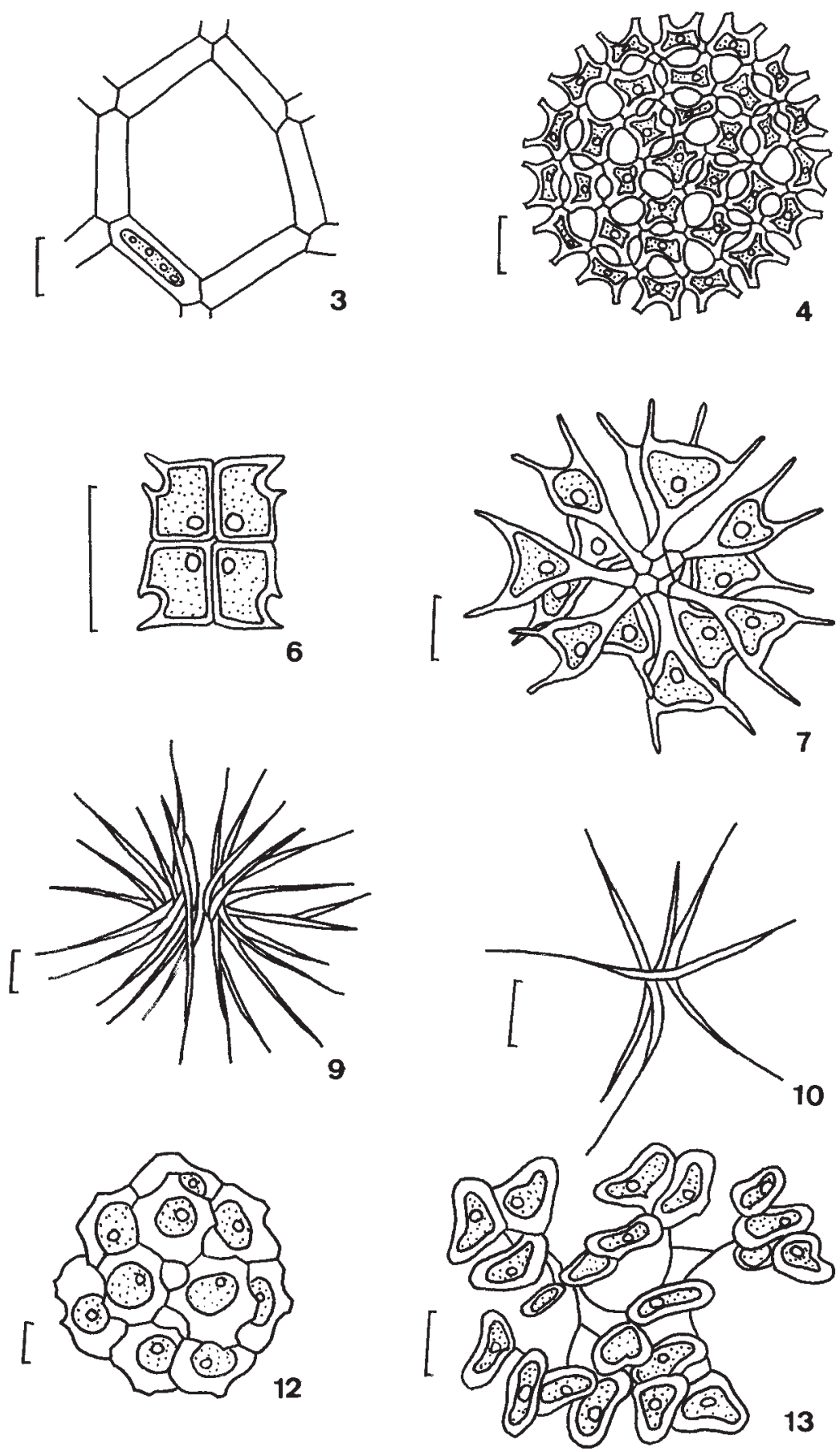

Figuras 2-13. 2. Sphaerocystis schroeteri. 3. Hydrodictyon reticulatum. 4. Pediastrum duplex var. duplex. 5. Pediastrum simplex var. simplex. 6. Pediastrum tetras var. tetras. 7. Sorastrum americanum var. americanum. 8. Dictyosphaerium pulchellum. 9. Ankistrodesmus densus. 10. Ankistrodesmus fusiformis. 11. Coelastrum astroideum var. astroideum. 12. Coelastrum pulchrum var. pulchrum. 13. Dimorphococcus lunatus. Barras de escala $=10 \mu \mathrm{m}$.

Figures 2-13. Sphaerocystis schroeteri. 3. Hydrodictyon reticulatum. 4. Pediastrum duplex var. duplex. 5. Pediastrum simplex var. simplex. 6. Pediastrum tetras var. tetras. 7. Sorastrum americanum var. americanum. 8. Dictyosphaerium pulchellum. 9. Ankistrodesmus densus. 10. Ankistrodesmus fusiformis. 11. Coelastrum astroideum var. astroideum. 12. Coelastrum pulchrum var. pulchrum. 13. Dimorphococcus lunatus. Scale bars $=10 \mu \mathrm{m}$. 
Figura 16

Cenóbios formados por 2-4 células dispostas linearmente; células cilíndricas a elípticas, pólos cônico-arredondados, as externas com um espinho longo nos ápices, costelas presentes em todas as células ou apenas nas internas, inteiras ou interrompidas na porção central da célula, podendo terminar em dentes nas células internas, 12-24,4 $\mu \mathrm{m}$ compr., 10-16,3 $\mu \mathrm{m}$ larg., esp. 6-9 um compr., dent. 0,4-1,2 $\mu \mathrm{m}$ compr.; cloroplasto parietal, com um pirenóide.

Material examinado: BRASIL. PARANÁ: Santa Helena, Rio São Francisco Falso, 6-X-2003, N C. Bueno 883 (HUEM); idem, 28-VII-2003, N.C. Bueno 862 (HUEM); idem, 1-IX-2003, N.C.Bueno 874 (HUEM); idem, 8-XII-2003, N.C. Bueno 902 (HUEM); idem, 4-V-2004, N.C. Bueno 933 (HUEM).

Ocorrência no Paraná: Lago Municipal de Cascavel (Moresco \& Bueno 2007).

Desmodesmus armatus var. bicaudatus (Guglielmetti) Hegewald, Arch. Hydrobiol. Suppl. 131:4. $2000 \equiv$ Scenedesmus acutiformis Schröder var. bicaudatus Guglielmetti, N. Not. 21: 31. 1910.

Figura 17

Cenóbios formados por (2-)4 células dispostas linearmente; células oblongas a reniformes, células externas com um espinho por ápice, disposto diagonalmente; costelas presentes em todas as células ou apenas nas internas, inteiras ou interrompidas na porção central da célula, podendo terminar em dentes. Célula 9,6-16,3 um compr., 7-15,2 $\mu \mathrm{m}$ larg.; esp. 3-5 $\mu \mathrm{m}$ compr.; dent. 0,8-1,1 $\mu \mathrm{m}$ compr.; cloroplasto parietal, com um pirenóide.

Material examinado: BRASIL. PARANÁ: Santa Helena, Rio São Francisco Falso, 1-IX-2003, N.C. Bueno 870 (HUEM).

Ocorrência no Paraná: Lago Municipal de Cascavel (Moresco \& Bueno 2007).

Desmodesmus armatus var. bicaudatus difere da variedade típica da espécie pela presença de apenas um espinho em cada um dos ápices das células externas disposto de forma diagonal no cenóbio.

Desmodesmus brasiliensis (Bohlin) Hegewald, Arch. Hydrobiol. Suppl. 131: 7. 2000 三 Scenedesmus brasiliensis Bohlin, Bih. K. Svenska Vet.-Akad. Handl. 23 (Afd. III, 7): 22. 1897.

Figura 18
Cenóbios formados por (2-)4-8 células dispostas linearmente; células elípticas ou oblongas, até cilíndricas, todas iguais, extremidades atenuadas, pólos levemente arredondados; costelas presentes em todas as células, inteiras ou fragmentadas, podendo se unir e formar 1-3 dentes nos pólos das células. Células 12-41 um compr., 8-19 um larg.; dent. 0,5-2 um compr.; cloroplasto parietal, com um pirenóide.

Material examinado: BRASIL. PARANÁ: Santa Helena, Rio São Francisco Falso, 1-IX-2003, N.C. Bueno 870 (HUEM); idem, 1-VII-2003, N.C. Bueno 855 (HUEM); idem, 1-IX-2003, N.C. Bueno 874 (HUEM); idem, 8-XII-2003, N.C. Bueno 902 (HUEM); idem, 6-X-2003, N.C. Bueno 882 (HUEM); idem,19-I-2004, N.C. Bueno 910 (HUEM).

Ocorrência no Paraná: Lago Municipal de Cascavel (Moresco \& Bueno 2007).

Desmodesmus communis (Hegewald) Hegewald, Arch.Hydrobiol.Suppl.131: 8.2000 $\equiv$ Scenedesmus communis Hegewald, Arch. Hydrobiol. Suppl. 51: 151. 1977.

Figura 19

Cenóbios formados por (2-)4-8(-16) células dispostas linearmente; células oblongas a trapezóides, pólos arredondados, as externas com um espinho longo e curvo nos ápices, 26-30,6 $\mu \mathrm{m}$ compr., 14,722,4 $\mu \mathrm{m}$ larg., esp. 12-17 um compr.; cloroplasto parietal, com um pirenóide.

Material examinado: BRASIL. Paraná: Santa Helena, Rio São Francisco Falso, 8-XII-2003, N.C. Bueno 902 (HUEM); idem, 17-VI-2004, N.C. Bueno 937 (HUEM); idem, 10-III-2004, N.C. Bueno 919 (HUEM); idem, 5-IV-2004, N.C. Bueno 928 (HUEM).

Ocorrência no Paraná: Parque Regional do Iguaçu (Picelli-Vicentim 1987); Parque Alfredo Nyffeler (Rodrigues \& Train 1993); Rio Paraná e Canal Cortado (Oliveira et al. 1994); Reservatório do Passaúna (Picelli-Vicentim et al. 2001) como Scenedesmus quadricauda (Turpin) Brébisson; Lago Municipal de Cascavel (Moresco \& Bueno 2007).

Segundo Sant'Anna (1984) Desmodesmus communis difere de D. protuberans (Fritsch \& Rich) Hegewald por apresentar todas as células do cenóbio com o mesmo comprimento, unidas por toda a extensão da parede celular e as células externas sem extremidades proeminentes. 
Desmodesmus denticulatus (Lagerheim) An, Friedl \& Hegewald var. denticulatus, Arch. Hydrobiol. Suppl. 131: 9. 2000 三Scenedesmus denticulatus Lagerheim Öfvers. K. [Svenska] Vet.-Akad. Förh. 39: 61. 1882.

Figura 20

Cenóbios de 4 células dispostas alternadamente; células ovóide-elípticas a amplamente ovóides, todas as células ou somente as externas com 1-4 dentes nos pólos, dispostos paralelamente ao eixo longitudinal do cenóbio ou levemente inclinados, 12,2-16,3 $\mu \mathrm{m}$ compr., 7-12 $\mu \mathrm{m}$ larg., dent. 0,5-1,2; cloroplasto parietal, com um pirenóide.

Material examinado: BRASIL. PARANÁ: Santa Helena, Rio São Francisco Falso, 1-IX-2003, N.C. Bueno 874 (HUEM); idem, 5-IV-2004, N.C.Bueno 925 (HUEM).

Ocorrência no Paraná: Parque Regional do Iguaçu (Picelli-Vicentim 1987); Rio Paraná e Canal Cortado (Oliveira et al 1994) como Scenedesmus denticulatus Lagerheim; Lago Municipal de Cascavel (Moresco \& Bueno 2007).

Desmodesmus denticulatus var. linearis (Hansgirg) Hegewald, Arch. Hydrobiol. Suppl. 131: 10.2000 =Scenedesmus denticulatus var. linearis Hansgirg, Prodr. Alg. Böhmen 1: 268. 1888.

Figura 21

Cenóbios de 2-4 células dispostas linearmente; células ovóides a oblongas, as externas com 1-2 dentes nos pólos, dispostos paralelamente, 14,3-20 um compr., 13-15,5 um larg., dent. 1-1,5 um compr.; cloroplasto parietal, com um pirenóide.

Material examinado: BRASIL. PARANÁ: Santa Helena, Rio São Francisco Falso, 1-VII-2003, N.C.Bueno 855 (HUEM); idem, 1-IX-2003, N.C. Bueno 870 (HUEM); idem, 1-IX-2003, N.C. Bueno 874 (HUEM); idem, 28-VII-2003, N.C.Bueno 862 (HUEM); idem, 8-XII2003, N.C.Bueno 902 (HUEM); idem, 3-II-2004, N.C. Bueno 915 (HUEM); idem, 4-V-2004, N.C. Bueno 933 (HUEM); idem, 5-IV-2004, N.C. Bueno 925 (HUEM).

Ocorrência no Paraná: Lago Municipal de Cascavel (Moresco \& Bueno 2007).

Desmodesmus denticulatus var. linearis difere da variedade típica da espécie por apresentar células ovóides a oblongas dispostas linearmente no cenóbio.

Desmodesmus protuberans (Fritsch \& Rich) Hegewald var. protuberans, Arch. Hydrobiol.
Suppl. 131: 16. $2000 \equiv$ Scenedesmus protuberans Fritsch \& Rich, Trans. Roy. Soc. S. Afr. 18: 31. 1929.

Figura 22

Cenóbios formados por (2-)4(-8-16) células dispostas linearmente; células elípticas, alongadas, a fusiformes, extremidades atenuadas, pólos proeminentes cônico-arredondados, margem externa da célula convexa, células externas com um espinho longo, curvo, células internas fusiformes, levemente menores, sem espinhos, extremidades abruptamente afiladas, pólos arredondados, 22,4-27,5 $\mu \mathrm{m}$ compr., 6-10 $\mu \mathrm{m}$ larg., esp. 15-20 um compr.; cloroplasto parietal, com um pirenóide.

Material examinado: BRASIL. PARANÁ: Santa Helena, Rio São Francisco Falso, 3-II-2004, N.C. Bueno 915 (HUEM); idem, 6-X-2003, N.C. Bueno 882 (HUEM).

Ocorrência no Paraná: Parque Regional do Iguaçu (Picelli-Vicentim 1987); Lago Municipal de Cascavel (Moresco \& Bueno 2007).

Desmodesmus protuberans assemelha-se muito a D. opoliensis, porém difere pelo formato das células, a primeira apresenta células com pólos proeminentes e cônico-arredondados e a segunda os pólos são truncados.

\section{Agradecimentos}

Os autores agradecem ao CNPq/PIBIC/ UNIOESTE pela bolsa de Iniciação Científica fornecida para o desenvolvimento do projeto e ao Laboratório de Perifíton do Nupélia, Núcleo de Pesquisas em Limnologia Ictiologia e Aqüicultura, da Universidade Estadual de Maringá pelo apoio nas pesquisas.

\section{Literatura citada}

Andrade, R.M. \& Rachou, R.G. 1954. Levantamento preliminar de organismos planctônicos em alguns criadouros do Anopheles darlingi no sul do Brasil. Revista Brasileira de Malariologia e Doenças Tropicais 6: 481-496.

Agostinho,A.A.,Okada,E.K.\& Gregoris,J.1999.APesca no Reservatório de Itaipu: Aspectos Socioeconômicos e Impactos do Represamento. In: R. Henry (ed.) Ecologia de reservatórios: estrutura, função e aspectos sociais. FAPESP/FUNDIBIO, Botucatu.

Bicudo, C.E.M. \& Menezes, M. 2006. Gênero de algas de águas continentais do Brasil: Chave para identificação e descrição. RiMa. São Carlos. 

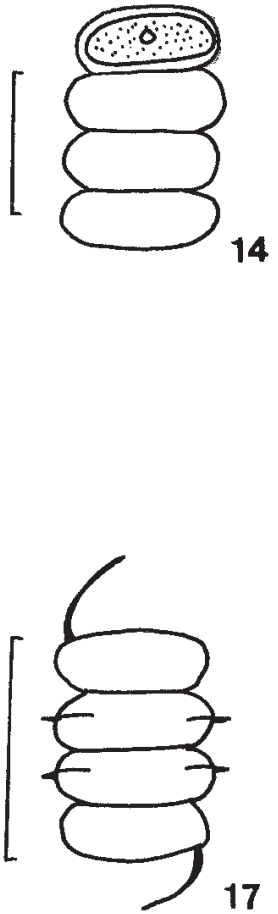

17

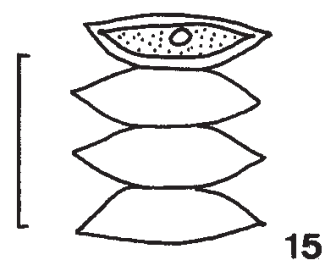

15

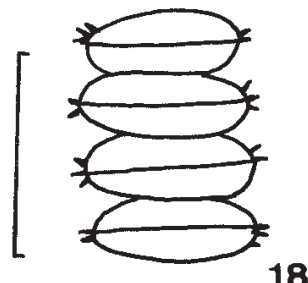

18
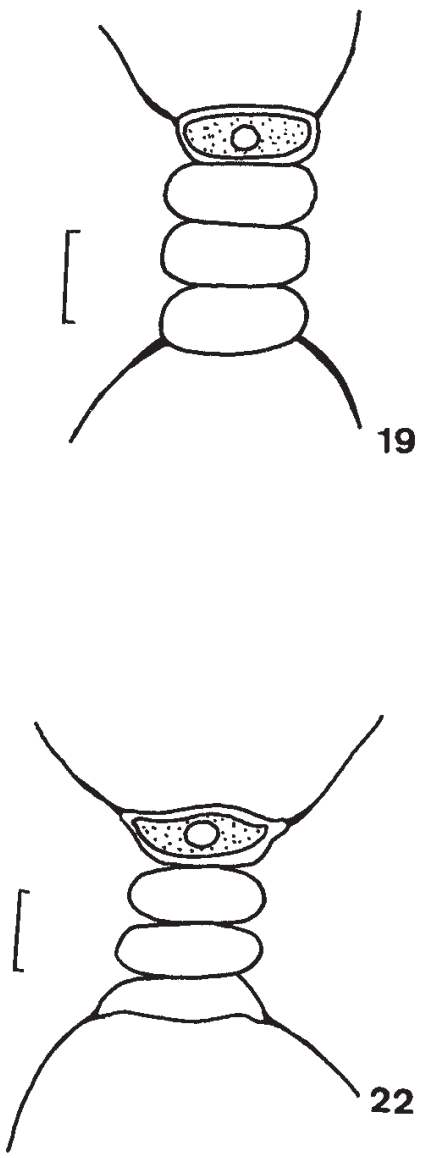

Figuras 14-22. 14. Scenedesmus acutus. 15. Scenedesmus ecornis. 16. Desmodesmus armatus var. armatus. 17. Desmodesmus armatus var. bicaudatus. 18. Desmodesmus brasiliensis. 19. Desmodesmus communis. 20. Desmodesmus denticulatus var. denticulatus. 21. Desmodesmus denticulatus var. linearis. 22. Desmodesmus protuberans. Barras de escala $=10 \mu \mathrm{m}$.

Figures 14-22. 14. Scenedesmus acutus. 15. Scenedesmus ecornis. 16. Desmodesmus armatus var. armatus. 17. Desmodesmus armatus var. bicaudatus. 18. Desmodesmus brasiliensis. 19. Desmodesmus communis. 20. Desmodesmus denticulatus var. denticulatus. 21. Desmodesmus denticulatus var. linearis. 22. Desmodesmus protuberans. Scale bars $=10 \mu \mathrm{m}$. 
Bittencourt-Oliveira, M.C. 1997. Fitoplâncton do Rio Tibagi, Estado do Paraná, Brasil: Nostocophyceae, Chlorophyceae, Euglenophyceae, Chrysophyceae e Tribophyceae. Hoehnea 24: 1-20.

Cecy, I.I.T. 1986. Estudo das algas microscópicas (Nostocophyta, Euglenophyta, Chrysophyta e Chlorophyta) do lago do Parque Barigui, em Curitiba, Estado do Paraná, Brasil. Arquivos de Biologia e Tecnologia 29: 383-405.

Comas, A. 1996. Las Chlorococcales dulciacuícolas de Cuba. Bibliotheca Phycologica 99:1-436.

Ettl, H. \& Gartner, G. 1988. Chlorophyta II. In: H. Ettl, J. Gerloff, H. Heynig \& D. Möllenhauer (eds.). Sübwasserflora von Mitteleuropa. Gustav Fischer Verlag, Stuttgart, pp. 1-436.

Felisberto, S.A., Rodrigues, L. \& Leandrini, J. A. 2001. Chlorococcales registradas na comunidade perifítica, no reservatório de Corumbá, Estado de Goiás, Brasil, antes e após o represamento das águas. Acta Scientiarum, Biological Sciences 23: 275-282.

Hegewald, E. 2000. New combinations in the genus Desmodesmus (Chlorophyceae, Scenedesmaceae). Algological Studies 96: 1-18.

Hegewald, E. \& Silva, G. 1988. Annotated catalogue of Scenedesmus and nomenclaturally rellated genera, including original descriptions and figures. Bibliotheca Phycologica 80: 1-578.

Komárek,J. \& Fott, B. 1983. Chlorophyceae (Grünalgen), Ordnung: Chlorococcales. In: G. Huber-Pestalozzi, H. Heynig \& D. Mollenhauer (eds.). Das Phytoplankton des Sübwassers. Systematic und biologie. E.
Schweizerbart'sche Verlagsbuchhandlung, Stuttgart, pp.1-1044.

Moreira Filho, H. \& Moreira, I.M.V. 1972. Observações sobre algas em águas de abastecimento. Tribuna Farmacêutica 40: 14-27.

Moresco, C. \& Bueno, N.C. 2007. Scenedesmaceae (Chlorophyceae - Chlorococcales) de um lago artificial urbano: Desmodesmus e Scenedesmus. Acta Scientiarum, Biological Sciences 29: 289-296.

Nogueira, I. S. 1991. Chlorococcales sensu lato (Chlorophyceae) do Município do Rio de Janeiro e Arredores, Brasil. Inventário e Considerações Taxonômicas. Dissertação de Mestrado, Universidade Federal do Rio de Janeiro, Rio de Janeiro.

Oliveira, M.D., Train, S. \& Rodrigues, L.C. 1994. Levantamento preliminar do fitoplâncton de rede (exceto Zygnemaphyceae) do Rio Paraná, no município de Porto Rico, Paraná, Brasil. Unimar 16: 155-174.

Picelli-Vicentim, M.M. 1987. Chlorococcales planctônicas do Parque Regional do Iguaçu, Curitiba, Estado do Paraná. Revista Brasileira de Biologia 47: 57-85.

Picelli-Vicentim, M.M., Treuersch, M. \& Domingues, L.L. 2001. Fitoplâncton da Represa do Passaúna, Estado do Paraná, Brasil. Hoehnea 28: 53-76.

Rodrigues L.C. \&Train, S. 1993. Chlorococcales planctônicas do Lago do Parque Alfredo Nyffeler, Maringá, Paraná, Brasil. Unimar 15: 19-35.

Sant'Anna, C.L. 1984. Chlorococcales (Chlorophyceae) do Estado de São Paulo, Brasil. Biblioteca Phycologica 67: 1-348. 